\title{
Phylogenetic analyses and toxigenic profiles of Fusarium equiseti and Fusarium acuminatum isolated from cereals from Southern Europe
}

\author{
Patricia Marín ${ }^{\mathrm{a}}$, Antonio Moretti ${ }^{\mathrm{b}}$, Alberto Ritieni ${ }^{\mathrm{c}}$, Miguel Jurado ${ }^{\mathrm{d}}$, Covadonga Vázquez ${ }^{\mathrm{e}}$, \\ M. Teresa González-Jaén ${ }^{\mathrm{a}, *}$
}

\begin{abstract}
A B S T R A C T
Fusarium equiseti and Fusarium acuminatum are toxigenic species that contaminate cereal crops from diverse climatic regions. They are common in Spanish cereals. The information available on their phylogenetics and toxigenic profiles is, however, insufficient to assist risk evaluation. In this work, phylogenetic analyses were performed using partial sequences of the translation elongation factor gene $(E F-1 \alpha)$ of $F$ equiseti and $F$. acuminatum strains isolated from barley and wheat from Spain and other countries. The Northern and Southern European F. equiseti strains largely separated into two phylogenetically distinct clusters. This suggests the existence of two distinct populations within this species, explaining its presence in these regions of markedly different climate. Production of type A and B trichothecenes by the Spanish strains, examined in wheat cultures using a multitoxin analytical method, indicated that $F$. equiseti could produce deoxynivalenol and nivalenol and other trichothecenes, at concentrations that might represent a significant risk of toxin contamination for Southern European cereals. F. acuminatum showed low intraspecific genetic variability and $58 \%$ of the strains could produce deoxynivalenol at low level. Neither species was found to produce T-2 or HT-2 toxins. The present results provide important phylogenetic and toxigenic information essential for the accurate prediction of toxigenic risk.
\end{abstract}

\section{Introduction}

Cereals are a dietary staple in most temperate regions. Unfortunately, they can become colonised by Fusarium, often resulting in severe crop disease, strongly reduced yields, and the accumulation of secondary metabolites toxic to humans and animals. Fusarium head blight (FHB) of small grain cereals is a disease complex that involves several Fusarium species causing largely indistinguishable symptoms. The species predominantly associated with FHB in Europe are Fusarium graminearum, Fusarium avenaceum and Fusarium poae (Nicholson et al., 2003; Somma et al., 2010; Xu et al., 2008). Less frequently isolated species are Fusarium tricinctum, Fusarium sporotrichioides, Fusarium equiseti, Fusarium langsethiae and Fusarium culmorum (Kosiak et al., 2003; Logrieco et al., 2003; $\mathrm{Xu}$ et al., 2005). Other species encountered sporadically include
Fusarium acuminatum, Fusarium subglutinans, Fusarium solani, Fusarium oxysporum, Fusarium semitectum, Fusarium verticillioides and Fusarium proliferatum (Logrieco et al., 2003). Climate change scenarios predict increasing temperatures and variations in water availability could induce changes in the profile of FHB species on cereals. Since each species has a characteristic mycotoxin profile, the risk of mycotoxin contamination of cereals might also change (Miraglia et al., 2009).

F. equiseti is a cosmopolitan fungus distributed across regions with cool through to hot and arid climates (Leslie and Summerell, 2006). It behaves as a soil saprophyte associated with rotting fruit and other decaying plant material, and as a pathogen of a wide range of crops. This species is often detected in Norwegian cereals (Kosiak et al., 2005), but it is also common in Southern Europe (Logrieco et al., 2003), particularly in Spain (Jurado et al., 2006a; Marín, 2010; Soldevilla et al., 2005). Further, it belongs to the socalled Fusarium incarnatum-F. equiseti species complex, a genetically highly diverse group (O'Donnell et al., 2009) the members of which are associated with human disease. 
F. acuminatum is widely distributed around the world, although mainly in temperate regions. It behaves as a soil saprophyte but is also found associated with the roots and crowns of plants (Leslie and Summerell, 2006; Pitt and Hocking, 2009). Its presence has recently been reported in Southern Europe, particularly Spain (Marín, 2010).

Both $F$. equiseti and $F$, acuminatum have been reported trichothecene producers (Adejumo et al., 2007; Kosiak et al., 2005; Logrieco et al., 1992). Trichothecenes are potent inhibitors of protein synthesis in eukaryotic cells (Brown et al., 2001), a consequence (mainly) of their interfering with peptidyl transferase activity. They cause different acute and severe diseases in humans and animals depending on the type of trichothecene ingested (Trenholm et al., 1989). F. equiseti produces trichothecenes such as T-2 toxin, 4-acetylnivalenol (FUS-X), deoxynivalenol (DON), nivalenol (NIV) and scirpentriol or its mono- and diacetyl derivatives (MAS and DAS) (Kosiak et al., 2005; Leslie and Summerell, 2006). It has been also reported to produce butenolide, beauvericin, equisetin (EQ), fusarochromanone (FUSCHR) and zearalenone (ZEA) (Leslie and Summerell, 2006). F. acuminatum has been reported to produce trace levels of trichothecene toxins such as diacetoxyscirpenol (DAS), monoacetoxyscirpenol (MAS), neosolaniol (NEO) and HT-2 toxin (HT-2) (Adejumo et al., 2007; Wing et al., 1993, 1994). Additionally, it produces enniatin B, steroids and moniliformin (Leslie and Summerell, 2006).

The identification of Fusarium species traditionally relies on the detection of morphological and physiological features. However, discrimination among similar species is often difficult. Neither do such methods detect intraspecific variability. Fortunately, phylogenetic analyses that make use of DNA sequence data have made significant contributions to our understanding of the systematics of Fusarium, providing species boundaries that are essential for establishing inter- and intraspecific relationships with respect to toxin profiles (Jurado et al., 2006a; Kristensen et al., 2005; Mirete et al., 2004; O'Donnell et al., 2009). Additionally, these techniques have provided the basis necessary for developing rapid, specific and accurate diagnostic methods based on PCR. These can be used to predict mycotoxin risk, providing the information necessary for early control strategies to be adopted (Jurado et al., 2005, 2006b; Knutsen et al., 2004; Konstantinova and Yli-Mattila, 2004). Several genomic sequences have been used to analyse intraspecific variability in Fusarium, including intron regions of histone coding genes, the $\beta$-tubulin gene ( $\beta$ TUB), the calmodulin gene (O'Donnell et al., 1998a; Steenkamp et al., 2002), and the translation elongation factor gene $E F-1 \alpha$ (O'Donnell et al., 1998b, 2000). $E F-1 \alpha$ gene has been used as a single-locus identification tool and is a suitable genetic marker for discriminating between Fusarium species (Geiser et al., 2004).

The literature contains little information regarding the phylogenetics of $F$. acuminatum. However, several reports suggest the existence of intraspecific diversity within $F$. equiseti (Kosiak et al., 2005; Kristensen et al., 2005; Jurado et al., 2006a). Kosiak et al. (2005) reported the existence of two groups with differences in morphological features and toxin production. However, the strains used in their study were basically all from Northern Europe. Later, a preliminary phylogenetic analysis conducted with $F$. equiseti strains from both Southern Europe (mostly isolated from Spanish cereals) and Northern Europe showed them to occupy one of two different clusters (Jurado et al., 2006a). The toxigenic profiles of the Spanish isolates were not analysed.

The aim of the present work was: (i) to examine, using partial EF$1 \alpha$ gene sequences, the phylogenetics of $F$ e equiseti and $F$. acuminatum strains isolated from cereal-producing regions in Spain, and (ii) to analyse the toxin profile of these Spanish strains in relation to their phylogenetics and those of Northern European strains.

\section{Material and methods}

\subsection{Fusarium strains}

Eight $F$. equiseti and $36 \mathrm{~F}$. acuminatum strains were isolated from barley cultivated in two different regions of Spain (Castilla y Léon and Castilla-La Mancha) in 2006 (Table 1). Fungal cultures were maintained on potato dextrose agar medium (PDA) (Scharlau Chemie, Barcelona, Spain) at $4{ }^{\circ} \mathrm{C}$ and stored as spore suspensions in $15 \%$ glycerol in our collection at the Complutense University of Madrid (UCM).

\subsection{DNA extraction and $P C R$ amplification of a partial sequence of $E F-1 \alpha$}

Genomic DNA extractions of pure cultures of eight strains of $F$. equiseti and 36 strains of $F$. acuminatum were undertaken using three mycelium disks excised from 5 to 7 day-old PDA plate cultures, and making use of the DNeasy Plant Mini Kit (Qiagen, Hilden, Germany) according to the manufacturer's instructions. A partial sequence of the $E F-1 \alpha$ gene was obtained by PCR using the primers and protocol described elsewhere (O'Donnell et al., 1998b). PCR-amplified fragments were purified using the UltraCleanTM PCR Clean-UpTM kit (MoBio Laboratories Inc., USA) according to the manufacturer's instructions. Automated sequencing of both DNA strands was performed with the $E F-1 \alpha$ pair of primers using a 3730 DNA Analyzer and the Big Dye ${ }^{\circledR}$ Terminator v 3.1 Cycle Sequencing Kit (Applied Biosystems, USA) at the UCM Genomic Unit. The sequences were corrected using Chromas v 1.43 software (Brisbane, Australia) and analysed and edited using Bioedit Sequence Alignment Editor v 7.0.9.0 software (Hall, 1999).

\subsection{Phylogenetic analyses}

Using PAUP v 4.0 b10 software (Swofford, 2003), individual maximum-parsimony (MP) phylogenetic analyses were performed for $F$. equiseti and $F$. acuminatum using the partial sequences of the $E F-1 \alpha$ gene obtained. Additional sequences previously obtained in our laboratory (Jurado et al., 2006a) were included, as were others retrieved from databases, along with sequences for species closely related to $F$. equiseti and $F$. acuminatum (Fusarium scirpi and $F$. avenaceum respectively). A total of 70 strains for $F$. equiseti and 63 for $F$ acuminatum were employed in the phylogenetic analyses (Table 1). An F. graminearum strain (AF212461) was used as an outgroup in both the F. equiseti or F. acuminatum MP analyses. Gaps were coded as missing data and were excluded from analyses. Unweighted parsimony analyses were performed on the individual data sets using the heuristic search option with 1000 random additional sequences with tree bisection-reconnection (TBR) branch swapping. Clade stability was assessed via 1000 bootstrap replications (Hillis and Bull, 1993). Additionally, phylogenetic analyses based on Neighbor Joining were performed using the Jukes-Cantor model (Jukes and Cantor, 1969).

Nucleotide diversities estimated as the average number of differences per site between two homologous sequences $(\pi)$ were calculated using DnaSp v 4.50 .3 software (Rozas et al., 2008), employing Eq. (10.5) of Nei (1987). Molecular diversities were calculated in each species for both the total sequence dataset and for the sequence dataset of each cluster. Gaps present in the alignment were excluded from analysis.

To determine the proportion of the total genetic variance attributable to inter-population differences, Wright's Fst statistic was determined via analysis of molecular variance (AMOVA) using the Arlequin v 3.01 software (Excoffier et al., 2005). The Wright's Fst statistic for the different groups was estimated using DNAsp v 


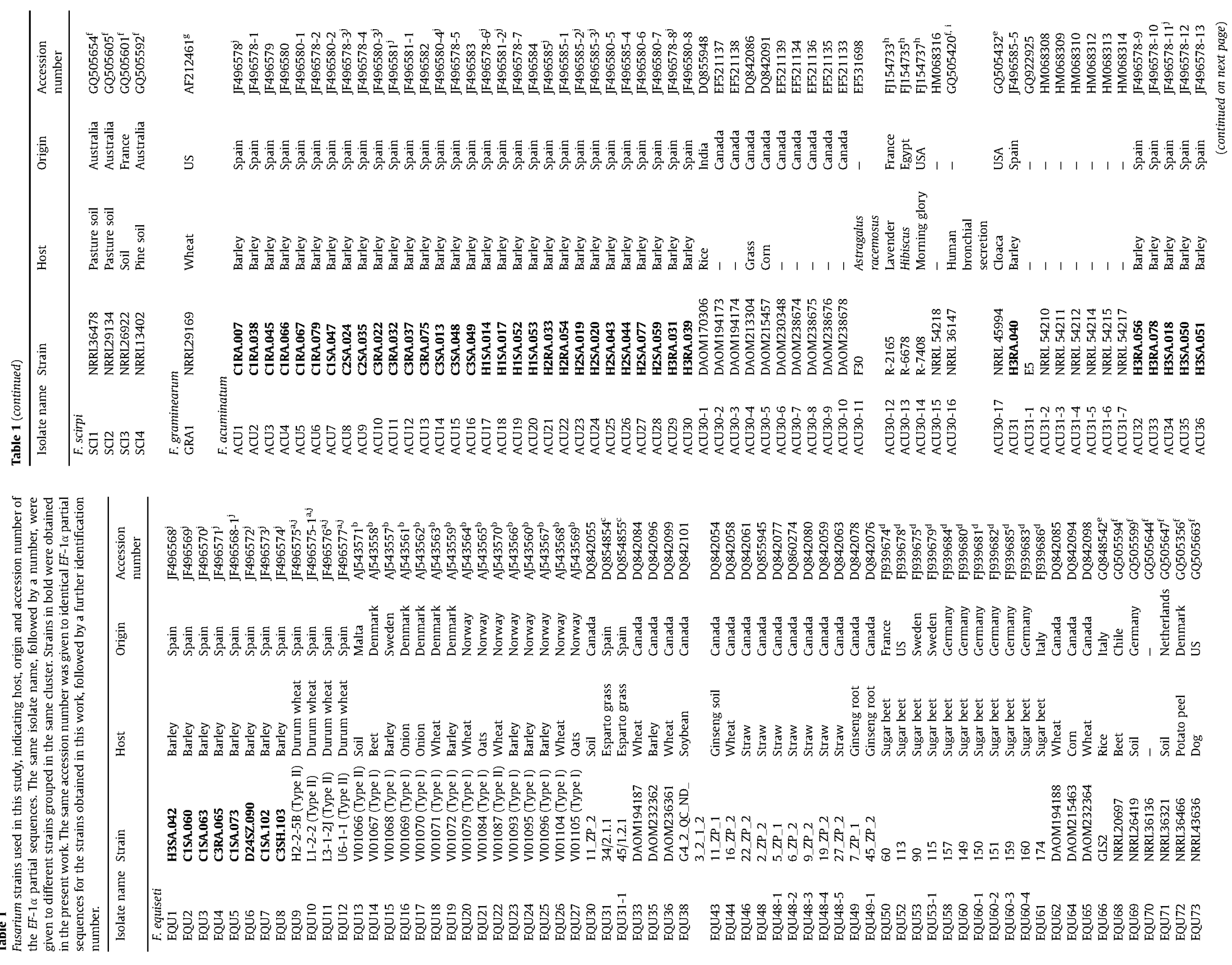


Table 1 (continued)

\begin{tabular}{|c|c|c|c|c|}
\hline Isolate name & Strain & Host & Origin & $\begin{array}{l}\text { Accession } \\
\text { number }\end{array}$ \\
\hline ACU50 & R-6934 & Soil & Australia & F[154736 ${ }^{\mathrm{h}}$ \\
\hline ACU52 & R-9382 & Chrysanthemum & China & FJ154738 h \\
\hline ACU59 & NRRL 54216 & - & - & HM068314 \\
\hline \multicolumn{5}{|c|}{ F. avenaceum } \\
\hline AVE1 & VI01057 & Wheat & Norway & AJ543518 \\
\hline \multicolumn{5}{|c|}{ a Jurado et al., 2006a. } \\
\hline \multicolumn{5}{|c|}{ b Kristensen et al., 2005.} \\
\hline \multicolumn{5}{|c|}{ c Maciá-Vicente et al., 2008.} \\
\hline \multicolumn{5}{|c|}{ d Nitschke et al., 2009.} \\
\hline \multicolumn{5}{|c|}{ e Amatulli et al., 2010.} \\
\hline \multicolumn{5}{|c|}{ f o'Donnell et al., 2009.} \\
\hline \multicolumn{5}{|c|}{ g o'Donnell et al., 2000.} \\
\hline \multicolumn{5}{|c|}{ h Nalim et al., 2009.} \\
\hline \multicolumn{5}{|c|}{ i O'Donnell et al., 2010} \\
\hline \multicolumn{5}{|c|}{${ }^{j}$ Isolates tested for trichothecene production. } \\
\hline
\end{tabular}

4.50 .3 software (Rozas et al., 2008) using Eq. (3) of Hudson et al. (1992) to take into account the genetic distances between the groups in both species.

To show more clear dendrograms for each species, the MP analyses were repeated eliminating some of the isolates that occurred in the same cluster in the first analyses, and which either had identical sequences or had differences of up to five singletons (non-parsimonious informative sites). These isolates were given the same name followed by different numbers. In both species, the dendrograms obtained in both the first and second MP analyses showed identical topologies. The same was also recorded when using the Jukes-Cantor model.

\subsection{Growth conditions for toxin detection}

Twelve strains of $F$. equiseti, including four isolated in a previous study (Jurado et al., 2006a) and 12 strains of $F$. acuminatum isolated in the present work were tested for trichothecene production (Table 1). Fifty gram samples of autoclaved wheat kept at a moisture content of $45 \%$ for one night were inoculated with a small quantity of each strain. Cultures were incubated at $25^{\circ} \mathrm{C}$ under fluorescent light (12 h photoperiod) for four weeks, then dried at $48{ }^{\circ} \mathrm{C}$ for $24 \mathrm{~h}$ and ground to a fine powder. Control (non-inoculated) wheat was treated in the same way.

\subsection{Chemical analysis}

A multitoxin analytical method, combining high-performance liquid chromatography (HPLC), atmospheric pressure chemical ionisation (APCI) and triple quadrupole tandem mass spectrometry (LC-MS/MS) under the selected reaction monitoring (SRM) mode, was used to detect the following mycotoxins: NIV, DON and its derivatives, FUS-X, NEO, HT-2, T-2 and DAS. Standards of these toxins were purchased from Sigma-Aldrich (Milan, Italy) and stored at $4{ }^{\circ} \mathrm{C}$ in the dark. The details of the procedure have been previously described (Somma et al., 2010). The limits of detection for NIV, DON, FUS-X, NEO, HT-2, T-2, DAS were 0.0033, 0.0005, $0.0015,0.0033,0.0033,0.001,0.0025$ and $0.001 \mu \mathrm{g} / \mathrm{g}$ respectively.

\section{Results}

\subsection{Phylogenetic analyses}

The amplification of $E F-1 \alpha$ produced a sequence of $616 \mathrm{bp}$ and 612 bp for $F$. equiseti and $F$. acuminatum respectively. In $F$. equiseti, the total number of nucleotides analysed, excluding indels, was 584. Of these, $95 \mathrm{nt}$ were polymorphic sites and 60 were parsimony-informative sites. In the case of $F$. acuminatum, excluding indels, the total number of nucleotides analysed was 589 . Of these, $11 \mathrm{nt}$ were polymorphic sites and $9 \mathrm{nt}$ were parsimonyinformative sites. Nucleotide diversities per site $(\pi)$ were $0.02846+0.00197$ (standard deviation) and $0.00433+0.00073$ for the $F$. equiseti and $F$. acuminatum $E F-1 \alpha$ sequences respectively.

Results from the first (data not shown) and second MP phylogenetic analyses (Figs. 1 and 2) generated the same $E F-1 \alpha$ genealogies for $F$. equiseti and for $F$. acuminatum. Figs. 1 and 2 show the bootstrap 50\% majority consensus trees based on MP analysis plus the consistency $(\mathrm{CI})$, retention (RI) and rescaled consistency (CR) indices. For $F$ e equiseti, both types of phylogenetic analysis (MP and Jukes-Cantor model [data not shown for the latter]) revealed three distinct clusters of isolates corresponding to F. equiseti types I and Il and $F$. scirpi. The genetic distance, in terms of Fst estimated using DNAsp software, between $F$. equiseti type I and type Il was 0.87166 , between $F$. equiseti type II and $F$. scirpi it was 0.56589 , and between $F$. equiseti type I and $F$. scirpi it was 0.63569 . The Fst fixation index value, determined by AMOVA for the three groups as a whole was 0.90646 . The F. equiseti type I and type II groups were homogeneous and showed low intra-group variability. The nucleotide diversity per site within these groups was $\pi=0.00359+0.00104$ and $\pi=0.00607 \pm 0.00110$ respectively. Variability was higher among the strains of the $F$. scirpi group ( $\pi=0.03026 \pm 0.00343$ ). The results did not support any influence of the host. However, the Northern European and Southern European $F$. equiseti strains largely separated into the type I and type II phylogenetic clusters (Fig. 1), with 16 of the 17 Spanish strains in the type II cluster and all 20 Northern European strains in the type I cluster. Strains from other locations (Table 1) fell into either the type I, type II or F. scirpi clusters.

The phylogenetic analyses revealed three defined groups for F. acuminatum (A, B and C) (Fig. 2) plus a set of sequences that did not belong to any of the above clusters. The Fst fixation index obtained for this species was 0.84570 . The intraspecific variability for the $E F-1 \alpha$ sequences was very low, with $\pi$ values between groups A, B and C less than 0.002 (data not shown).

\subsection{Toxin production}

To characterize the chemical profile of $F$. equiseti and F. acuminatum toxin production, 12 isolates of each species were examined (Table 2). None of the 12 isolates of $F$. equiseti tested produced $3 / 15 \mathrm{Ac}-\mathrm{DON}$, and none of the $12 \mathrm{~F}$. acuminatum isolates produced NIV, 3/15Ac-DON, DON derivatives, NEO or DAS. T-2 and HT-2 were absent in all cultures of both species. In F. equiseti, NIV, DON, DON derivatives, FUS-X, NEO and DAS were produced by 3 (25\%), 10 (83.33\%), 4 (33.33\%), 5 (41.67\%), 3 (25\%) and $3(25 \%)$ isolates respectively (Table 3 ). Production levels were very variable, ranging from 227 to $7005 \mu \mathrm{g} / \mathrm{kg}$ for NIV, from 46 to $1035 \mu \mathrm{g} / \mathrm{kg}$ for DON, from 367.5 to $10,150 \mu \mathrm{g} / \mathrm{kg}$ for DON derivatives, from 32.5 to $16,750 \mu \mathrm{g} / \mathrm{kg}$ for FUS-X, from 38.1 to $1665 \mu \mathrm{g} / \mathrm{kg}$ for NEO, and from 9.65 to $197 \mu \mathrm{g} / \mathrm{kg}$ for DAS. In F. acuminatum the production of DON and FUS-X was detected in 7 (58.33\%) and 1 (8.33\%) isolate respectively. The production level was constant, ranging from 45.1 to $61.1 \mu \mathrm{g} / \mathrm{kg}$ for DON, and from 32.5 to $16,750 \mu \mathrm{g} / \mathrm{kg}$ for FUS-X (Table 3). Three isolates of $F$. equiseti produced both type A (NEO and DAS) and type B (NIV, DON, 3/15Ac-DON, DON derivatives and FUS-X) trichothecenes, whereas seven produced only type $B$ trichothecenes. Only two isolates produced no type of trichothecene. In F. acuminatum, seven isolates produced only DON, and only one of these produced FUS-X. Five isolates did not produce any of the trichothecenes analysed (Table 2). 


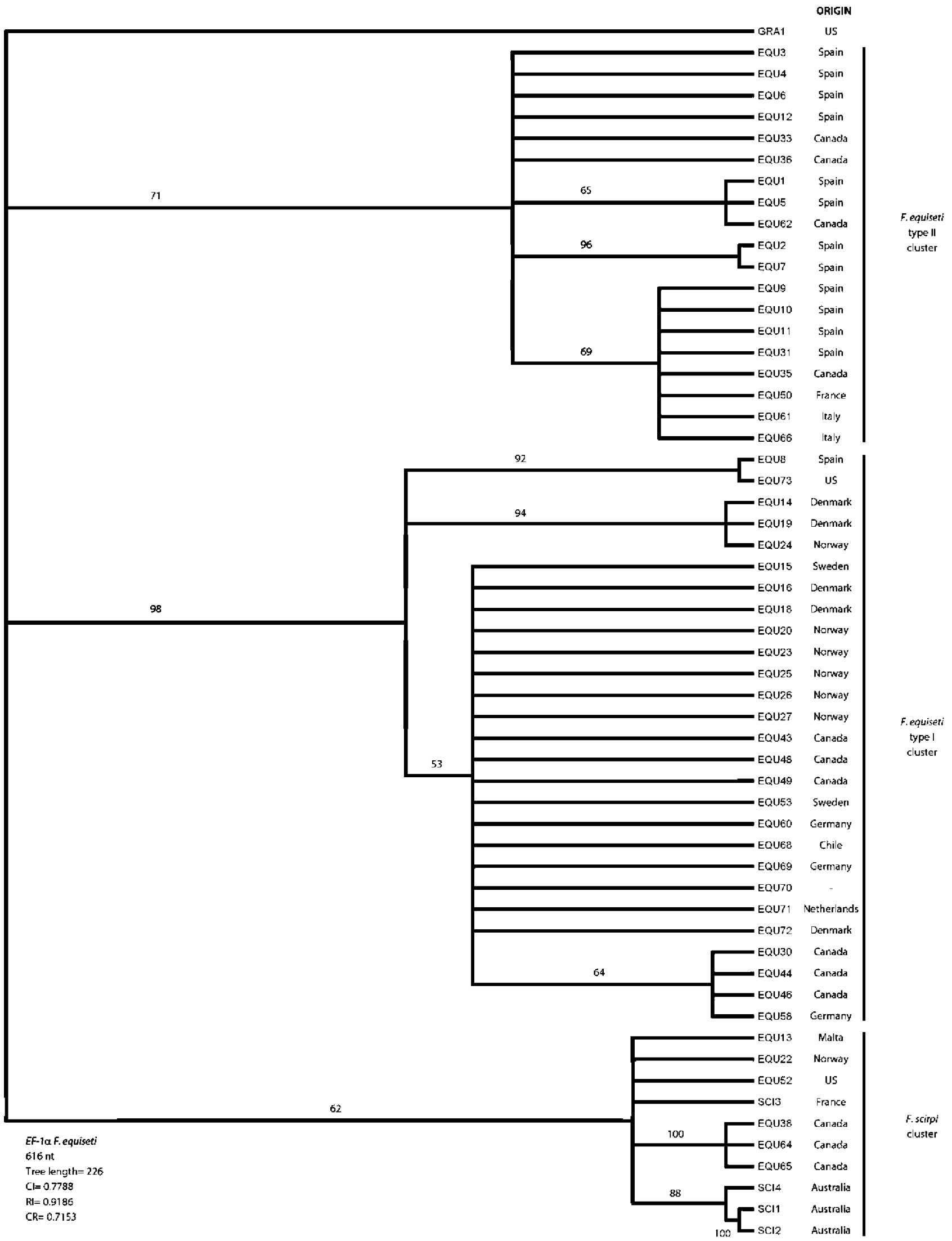

Fig. 1. Bootstrap 50\% majority-rule consensus tree based on MP analysis of $F$. equiseti isolates. CI: Consistency index, RI: Retention index, CR: Rescaled consistency index. 


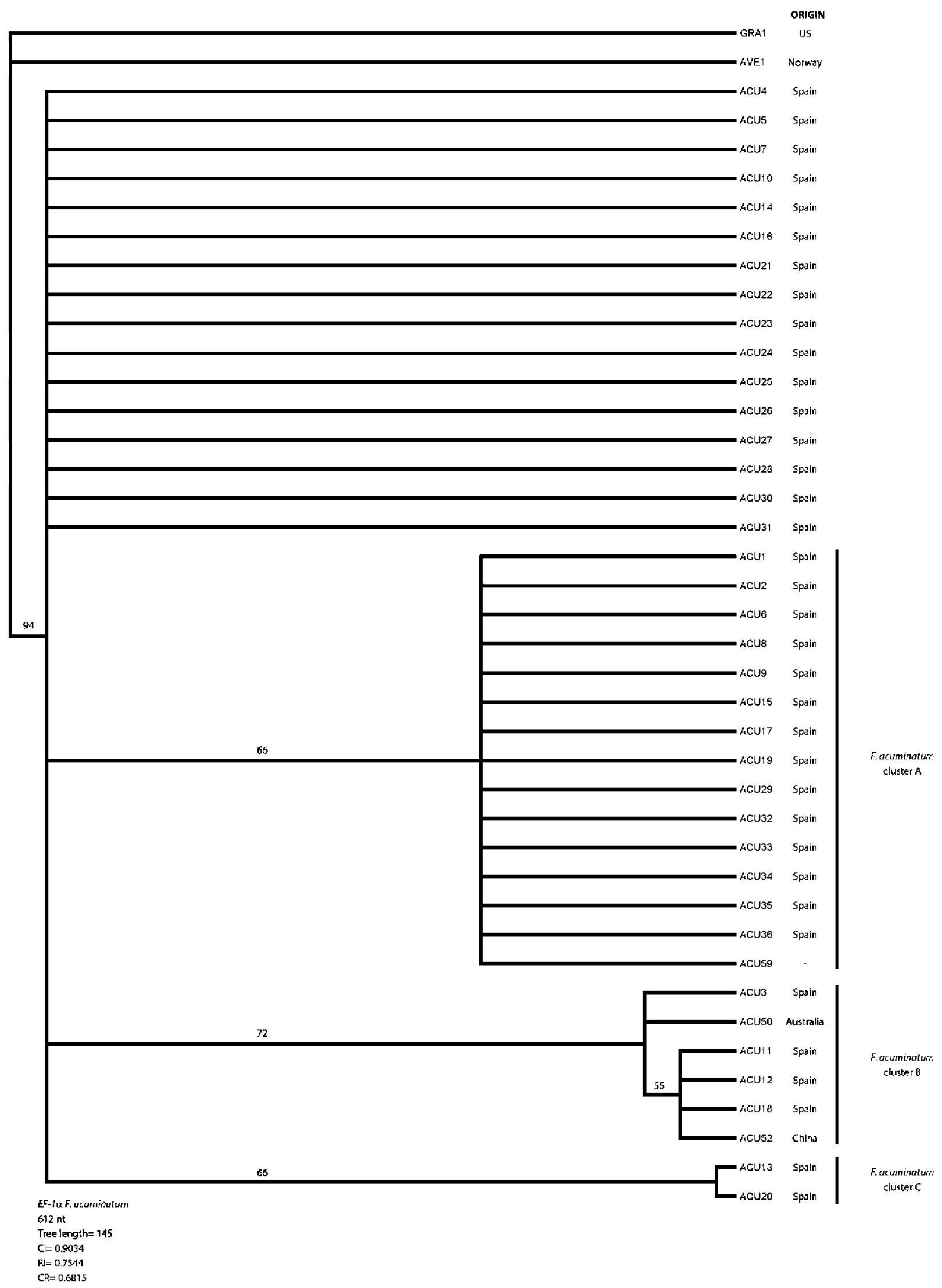

Fig. 2. Bootstrap 50\% majority-rule consensus tree based on MP analysis of $F$. acuminatum strains. CI: Consistency index, RI: Retention index, CR: Rescaled consistency index. 


\section{Table 2}

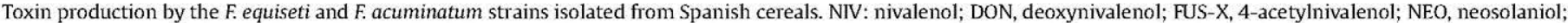

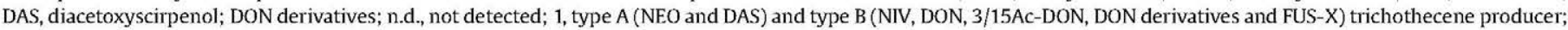
2, type A trichothecene producer; 3 , type B trichothecene producer; 4 non-trichothecene producer.

\begin{tabular}{|c|c|c|c|c|c|c|c|c|}
\hline \multirow[t]{3}{*}{ Isolate Name } & \multicolumn{7}{|c|}{ Toxin production $(\mu \mathrm{g} / \mathrm{kg})$} & \multirow[t]{3}{*}{ Toxin profile } \\
\hline & \multicolumn{5}{|c|}{ Type B trichothecene } & \multicolumn{2}{|c|}{ Type A trichothecene } & \\
\hline & NIV & DON & 3/15Ac-DON & DON derivatives & FUS-X & NEO & DAS & \\
\hline \multicolumn{9}{|l|}{ F. equiseti } \\
\hline EQU1 (type II) & n.d. & n.d. & n.d. & n.d. & n.d. & n.d. & n.d. & 4 \\
\hline EQU2 (type II) & n.d. & 46 & n.d. & n.d. & n.d. & n.d. & n.d. & 3 \\
\hline EQU3(type II) & n.d. & 62.4 & n.d. & n.d. & n.d. & n.d. & n.d. & 3 \\
\hline EQU4 (type II) & n.d. & n.d. & n.d. & n.d. & n.d. & n.d. & n.d. & 4 \\
\hline EQU5 (type II) & 119.5 & 67.01 & n.d. & 118.5 & 121 & n.d. & n.d. & 3 \\
\hline EQU6 (type II) & n.d. & 61.5 & n.d. & n.d. & n.d. & n.d. & n.d. & 3 \\
\hline EQU7 (type II) & 7005 & 1035 & n.d. & 10150 & 16750 & 1665 & 197 & 1 \\
\hline EQU8 (type I) & n.d. & 52.1 & n.d. & n.d. & n.d. & n.d. & n.d. & 3 \\
\hline EQU9 (type II) & n.d. & 116.5 & n.d. & 578.5 & 2320 & 60.65 & 15.9 & 1 \\
\hline EQU10 (type II) & 227 & 62.3 & n.d. & 367.5 & 1115 & 38.1 & 9.65 & 1 \\
\hline EQU11(type II) & n.d. & 56.55 & n.d. & n.d. & n.d. & n.d. & n.d. & 3 \\
\hline EQU12 (type II) & n.d. & 60.35 & n.d. & n.d. & 32.5 & n.d. & n.d. & 3 \\
\hline \multicolumn{9}{|l|}{ F. acuminatum } \\
\hline ACU1 & n.d. & 58.65 & n.d. & n.d. & n.d. & n.d. & n.d. & 3 \\
\hline ACU8 & n.d. & 48.4 & n.d. & n.d. & n.d. & n.d. & n.d. & 3 \\
\hline ACU10 & n.d. & 60.11 & n.d. & n.d. & 46.7 & n.d. & n.d. & 3 \\
\hline ACU11 & n.d. & 61.1 & n.d. & n.d. & n.d. & n.d. & n.d. & 3 \\
\hline ACU14 & n.d. & n.d. & n.d. & n.d. & n.d. & n.d. & n.d. & 4 \\
\hline ACU17 & n.d. & n.d. & n.d. & n.d. & n.d. & n.d. & n.d. & 4 \\
\hline ACU18 & n.d. & 58.2 & n.d. & n.d. & n.d. & n.d. & n.d. & 3 \\
\hline ACU21 & n.d. & 45.1 & n.d. & n.d. & n.d. & n.d. & n.d. & 3 \\
\hline ACU23 & n.d. & 58.35 & n.d. & n.d. & n.d. & n.d. & n.d. & 3 \\
\hline ACU24 & n.d. & n.d. & n.d. & n.d. & n.d. & n.d. & n.d. & 4 \\
\hline ACU29 & n.d. & n.d. & n.d. & n.d. & n.d. & n.d. & n.d. & 4 \\
\hline ACU34 & n.d. & n.d. & n.d. & n.d. & n.d. & n.d. & n.d. & 4 \\
\hline
\end{tabular}

\section{Discussion}

Accurate predictions of mycotoxigenic risk basically rely on the correct identification of the fungal species in agrofood products and the determination of the toxigenic profiles of strains from different origins that might adequately represent the species. Conventional methods for identifying fungal species may overlook diversity at intraspecific level, i.e., the existence of cryptic populations. Phylogenetic analyses, however, provide a useful tool for revealing such populations, they can efficiently assist in the identification of fungal strains, and permit toxigenic profiles to be associated with particular populations or species. In the present work this approach was used to investigate a sample of isolates from two Fusarium species,

Table 3

Percentage of $F$. equiseti and $F$. acuminatum strains producing any of the toxins tested in this study, and the minimum and maximum quantities produced. NIV: nivalenol; DON, deoxynivalenol; FUS-X, 4-acetylnivalenol; NEO, neosolaniol; DAS, diacetoxyscirpenol; DON derivatives; n.d., not detected.

\begin{tabular}{lllr} 
& \multicolumn{3}{c}{$\begin{array}{l}\text { Toxin production } \\
(\mu \mathrm{g} / \mathrm{kg})\end{array}$} \\
\cline { 3 - 4 } Toxin & $\begin{array}{l}\text { Producer } \\
\text { isolates }(\%)\end{array}$ & Minimum & Maximum \\
& & & \\
\hline F. equiseti & 25 & 227 & 7005 \\
NIV & 83.33 & 46 & 1035 \\
DON & 33.33 & 367.5 & 10150 \\
DON derivatives & 41.67 & 32.5 & 16750 \\
FUS-X & 25 & 38.1 & 1665 \\
NEO & 25 & 9.65 & 197 \\
DAS & & & 61.1 \\
& & 75.1 & 46.7 \\
F. acuminatum & 58.33 & 46.7 & \\
DON & 8.33 & & \\
FUS-X & & & \\
\hline
\end{tabular}

F. equiseti and F. acuminatum, which often occur in cereals grown in Spain, and which have not been characterized to date. Their phylogenetic analysis also included a representative sample of isolates of different origin in order to situate them within a wider geographical context, particularly that of Europe.

The phylogenetic results for $F$. equiseti reveal the existence of wide genetic variability and two different clusters, type I and type II, that predominantly group the Northern and Southern European F. equiseti strains respectively. These results agree with those of a previous study by our group (Jurado et al., 2006a). Further, four out of five strains from Northern Europe described by Kosiak et al. (2005) fell into the type I cluster, while the other fell into the F. scirpi cluster. The existence of two distinct populations within this species might explain its presence in these two regions of markedly different climate. The genetic isolation of these two populations (which would depend greatly on the amount of sexual reproduction practised) may have occurred and genetic differences providing better adaptation to ecophysiological factors may have arisen in both. Although the life cycle of $F$. equiseti includes the perfect stage Gibberella intrincans (Leslie and Summerell, 2006), perithecia of $G$. intrincans have only been observed in laboratory experiments. Therefore, the predominant mode of reproduction of $F$. equiseti is considered to be asexual. If no sexual events occur between the two proposed populations, the different features and toxigenic profiles of each will persist. Additional studies would be useful for characterizing these two populations, including an examination of the ecophysiological characteristics of individuals from both populations and their relationship with their climatologically different origins.

Several studies indicate that $F$. equiseti strains can produce a wide array of toxins (Adejumo et al., 2007; Kosiak et al., 2005). In the present study, the toxigenic profile of the type II Spanish strains showed differences with respect to previously reported 
strains from Northern Europe (Kosiak et al., 2005), which fell into the type I cluster. In neither set of strains, however, was the production of toxins T-2 nor HT-2 detected. Kosiak et al. (2005) reported $F$. equiseti strains to produce higher quantities of type A trichothecenes, no detectable levels of DON nor DON derivatives, but significant amounts of NIV and FUS-X. In the present study, the Spanish $F$. equiseti strains did produce DON, DON derivatives and the highly toxic NIV at higher levels. Over $80 \%$ of the strains produced at least DON and 25\% produced NIV as well. Further, the type II population showed diversity among individuals regarding the set of toxins produced and the relative quantities manufactured. In any event, the low level of non-toxigenic strains (less than $20 \%$ ), the importance of some of the toxins produced, and their wide occurrence in cereals, highlight the potential contribution of F. equiseti to the toxin risk associated with the consumption of Spanish cereals, as well as the need to design early detection and control strategies for this species. The PCR-based $F$. equiseti detection protocol (Jurado et al., 2005, 2006b) may be useful in this respect.

The topology of the dendrogram obtained, which included the closely related species $F$. scirpi as a reference, suggests that further studies are needed for clear species distinctions to be made. Indeed, the present results, and those of a recent study on the clinically important $F$. incarnatum $-F$. equiseti species complex involving the use of multilocus DNA sequence data (O'Donnell et al., 2009), show the strong variability of $F$. equiseti and $F$. scirpi. O'Donnell et al. (2009) concluded that the $F$. incarnatum-F. equiseti complex contained 28 phylogenetically distinct species in which both $F$. equiseti and $F$. scirpi were represented in two distinct clusters. These $F$. equiseti and $F$. scirpi strains were also included in the present phylogenetic study, and they clustered within F. equiseti type I and F. scirpi respectively. Unfortunately, it would seem that no isolate of F. equiseti type II was included in the study performed by O'Donnell et al. (2009). Further studies should examine a fully representative sample of the diversity of $F$. equiseti in order to obtain a reliably robust phylogeny.

Diversity was also found for $F$. acuminatum, with different clusters detected, although no relationship with host or geographic origin could be established (all these groups contained $F$. acuminatum strains isolated from Spanish barley). However, analyses of the $E F-1 \alpha$ genomic sequence revealed less intraspecific variability than that recorded for $F$. equiseti, with a low number of parsimony-informative sites and little nucleotide diversity despite the different origins of the strains analysed. Thus, these results are suggestive of a quite homogenous population. This species is clearly phylogenetically distinct from other related species with similar morphological features within the $F$. avenaceum/F. acuminatum/F. tricinctum species complex (Harrow et al., 2010; Leslie and Summerell, 2006). Harrow et al. (2010) suggest that $F$. acuminatum may not be as abundant as F. avenaceum, probably as a consequence of biogeographic limitation, narrow host preferences and/or competitive disadvantages restricting its presence in different environments, and indicate that this might be related to the scant variability it shows. As mentioned above, a number of authors have reported different toxigenic profiles for $F$. acuminatum. However, to our knowledge, the production of DON by $F$. acuminatum has not been previously reported. In the present study seven out of 12 strains analysed were able to produce DON, although at a very low level. This suggests that this species should not be considered a DON non-producing species, although additional studies are needed to confirm this. The potential toxin risk of DON contamination should not, therefore, be dismissed. A study including both phylogenetic and toxin analyses are essential for accurate predictions of toxin risk since this could detect intraspecific variability that otherwise might be overlooked, and associate toxigenic profiles to groups/lineages/species.
In summary, the present results suggest the existence of two phylogenetically distinct populations of $F$. equiseti apparently associated with two different geographical/climatic regions: Northern and Southern Europe (type I and type II respectively). Toxin production by the type II population indicates that its members could pose a risk of cereal contamination in Southern Europe, particularly involving DON and NIV. In the case of F. acuminatum, although the potential DON risk is probably small, it should not be disregarded.

\section{Acknowledgements}

The authors are grateful to Dr. Nieves Aparicio (Instituto Tecnológico Agrario de Castilla y León, ITACyL) and to the Instituto Técnico Agronómico Provincial de Albacete (ITAP) for providing barley samples. This work was supported by the Spanish MCIN (AGL2010-22182-C04-01) and by the BSCH-UCM (GR35/10-A).

\section{References}

Adejumo, T.O., Hettwer, U., Karlovsky, P., 2007. Occurrence of Fusarium species and trichothecene in Nigerian maize. International Journal of Food Microbiology $166,350-357$.

Amatulli, M.T., Spadaro, D., Gullino, M.L., Garibaldi, A., 2010. Molecular identification of Fusarium spp. associated with bakanae disease of rice in Italy and assessment of their pathogenicity. Plant Pathology 59, 839-844.

Brown, D.W., McCormick, S.P., Alexander, N.J., Proctor, R.H., Desjardins, A.E., 2001 A genetic and biochemical approach to study trichothecene diversity in Fusarium sporotrichioides and Fusarium graminearum. Fungal Genetics Biology 32, 121-133.

Excoffier, L., Laval, G., Schneider, S., 2005. Arlequin ver. 3.0: an integrated software package for population genetics data analysis. Evolutionary Bioinformatics Online $1,47-50$.

Geiser, D.M., Jiménez-Gasco, M.M., Kang, S., Makalowska, I., Veeraraghavan, N., Ward, T.J., Zhang, N., Kuldau, G.A., O'Donnell, K., 2004. FUSARIUM-ID v. 1.0: a DNA sequence database for identifying Fusarium. European Journal of Plant Pathology $110,473-479$.

Hall, T.A., 1999. BioEdit: a user-friendly biological sequence alignment editor and analysis program for Windows 95/98/NT. Nucleic Acids Symposium Series 41, 95-98.

Harrow, S.A., Farrokhi-Nejad, R., Pitman, A.R., Scott, I.A.W., Bentley, A., Hide, C., Cromey, M.G., 2010. Characterization of New Zealand Fusarium populations using a polyphasic approach differentiates the $F$. avenaceum/F. acuminatum/ F. tricinctum species complex in cereal and grassland systems. Fungal Biology $114,193-311$.

Hillis, D.M., Bull, J.J., 1993. An empirical test of bootstrapping as a method for assessing confidence in phylogenetic analysis. Systematic Biology 42, 182-192.

Hudson, R.R., Slatkin, M., Maddison, W.P., 1992. Estimation of levels of gene flow from DNA sequence data. Genetics $132,583-589$

Jukes, T.H., Cantor, C.R., 1969. Evolution of protein molecules. In: Mammalian Protein Metabolism. Academic Press, New York, USA, pp. 21-132.

Jurado, M., Vázquez, C., Patiño, B., González-Jaên, M.T., 2005. PCR detection assay for the trichothecene-producing species Fusarium graminearum, Fusarium culmorum, Fusarium poae, Fusarium equiseti and Fusarium sporotrichioides. Systematic and Applied Microbiology 28, 562-568.

Jurado, M., Vázquez, C., Callejas, C., González-Jaên, M.T., 2006a. Occurrence and variability of mycotoxigenic Fusarium species associated to wheat and maize in the South of Spain. Mycotoxin Research 22, 87-91.

Jurado, M., Vázquez, C., Marín, S., Sanchis, V., González-Jaén, M.T., 2006b. PCR-based strategy to detect contamination with mycotoxigenic Fusarium species in maize. Systematic and Applied Microbiology 29, 681-689.

Knutsen, A.K., Torp, M., Holst-Jesen, A., 2004. Phylogenetic analyses of Fusarium poae, Fusarium sporotrichioides and Fusarium Langsethiae species complex based on partial sequences of translation elongation factor 1 alpha gene. International Journal of Food Microbiology 95, 287-295.

Konstantinova, P., Yli-Mattila, T., 2004. IGS-RFLP analysis and development of molecular markers for identification of Fusarium poae, Fusarium langsethiae, Fusarium sporotrichioides and Fusarium kyushuense. International Journal of Food Microbiology 95, 321-331.

Kosiak, B., Torp, M., Skjerve, E., Thrane, U., 2003. The prevalence and distribution of Fusarium species in Norwegian cereals: a survey. Acta Agriculturae Scandinavica, Section B - Soil \& Plant Science 53, 168-179.

Kosiak, E.B., Holst-Jensen, A., Rundberget, T., González-Jaén, M.T., Torp, M., 2005 Morphological, chemical and molecular differentiation of Fusarium equiseti isolated from Norwegian cereals. International Journal of Food Microbiology 99 195-206.

Kristensen, R., Torp, M., Kosiak, B., Holst-Jensen, A., 2005. Phylogeny and toxigenic potential is correlated in Fusarium species as revealed by partial translation elongation factor 1 alpha gene sequences. Mycological Research 109, 173-186. 
Leslie, J.F., Summerell, B.A., 2006. The Fusarium Laboratory Manual, first ed. Blackwell Publishing, lowa, USA.

Logrieco, A., Altomare, C., Moretti, A., Bottalico, A., 1992. Cultural and toxigenic variability in Fusarium acuminatum. Mycological Research 96, 518-523.

Logrieco, A., Bottalico, A., Mulé, G., Moretti, A., Perrone, G., 2003. Epidemiology of toxigenic fungi and their associated mycotoxins for some Mediterranean crops. European Journal of Plant Pathology 109, 645-667.

Maciá-Vicente, J.G., Jansson, H.B., Abdullah, S.K., Descals, E., Salinas, J., LopezLlorca, L.V., 2008. Fungal root endophytes from natural vegetation in Mediterranean environments with special reference to Fusarium spp. FEMS Microbiology Ecology 64, 90-105.

Marín, P., 2010. Análisis de factores ecofisiológicos que influyen en la expresión de genes relacionados con la biosintesis de toxinas en especies de Fusarium. $\mathrm{PhD}$ Thesis. University Complutense of Madrid.

Miraglia, M., Marvin, H.J.P., Kleter, G.A., Battilani, P., Brera, C., Coni, E., Cubadda, F. Croci, L., De Santis, B., Dekkers, S., Filippi, L., Hutjes, R.W.A., Noordam, M.Y. Pisante, M., Piva, G., Prandini, A., Toti, L., Van Den Born, G.J., Vespermann, A. 2009. Climatic change and food safety: an emerging issue with special focus on Europe. Food and Chemical Toxicology 47, 1009-1021.

Mirete, S., Vázquez, C., Mulè, G., Jurado, M., González-Jaén, M.T., 2004. Differentiation of Fusarium verticillioides from banana fruits by IGS and EF-1 $\alpha$ sequence analyses. European Journal of Plant Pathology 110, 515-523.

Nalim, F.A., Elmer, W.H., McGovern, R.J., Geiser, D.M., 2009. Multilocus phylogenetic diversity of Fusarium avenaceum pathogenic on lisianthus. Phytopathology 99 462-468.

Nei, M., 1987. Molecular Evolutionary Genetics. Columbia University Press, New York, USA.

Nicholson, P., Chandler, E., Draeger, R.C., Gosman, N.E., Simpson, D.R., Thomsett, M. Wilson, A.H., 2003. Molecular tools to study epidemiology and toxicity of Fusarium head blight of cereals. European Journal of Plant Pathology 109, 691-703.

Nitschke, E., Nihlgard, M., Varrelmann, M., 2009. Differentiation of eleven Fusarium spp. isolated from sugar beet, using restriction fragment analysis of a polymerase chain reaction-amplified translation elongation factor 1 alpha gene fragment. Phytopathology 99, 921-929.

o'Donnell, K., Cigelnik, E., Nirenberg, H.l., 1998a. Molecular systematics and phylogeography of the Gibberella fujikuroi species complex. Mycologia 90, 465-493.

O'Donnell, K., Kistler, H.C., Cigelnik, E., Ploetz, R.C., 1998b. Multiple evolutionary origins of the fungus causing Panama disease of banana: concordant evidence from nuclear and mitochondrial gene genealogies. Proceedings of the National Academy of Sciences 95, 2044-2049.

O'Donnell, K., Kistler, H.C., Tacke, B.K., Casper, H.H., 2000. Gene genealogies reveal global phylogeographic structure and reproductive isolation among lineages of Fusarium graminearum, the fungus causing wheat scab. Proceedings of the National Academy of Sciences of the United States of America 97, 7905-7910.
O'Donnell, K., Sutton, D.A., Rinaldi, M.G., Gueidan, C., Crous, O.W., Geiser, D.M., 2009. Novel multilocus sequence typing scheme reveals high genetic diversity of human pathogenic members of the Fusarium incarnatum-F. equiseti and F. chlamydosporum species complexes within the United States. Journal of Clinical Microbiology 47, 3851-3861.

O'Donnell, K Sutton, D.A, Rinaldi, MG Sarver, BA, Balajee, SA Schroers, H J, Summerbell, R.C., Robert, V.A., Crous, P.W., Zhang, N., Aoki, T., Jung, K., Park, J., Lee, Y.H., Kang, S., Park, B., Geiser, D.M., 2010. An internet-accessible DNA sequence database for identifying Fusaria from human and animal infections. Journal of Clinical Microbiology 48, 3708-3718.

Pitt, J.l., Hocking, A.D., 2009. Fungi and Food Spoilage, third ed. Springer Science+Business Media, New York, USA.

Rozas, J., Sánchez-Del Barrio, J.C., Messenguer, X., Rozas, R., 2008. Dnasp, DNA polymorphism analyses by the coalescent and other methods. Bioinformatics 19, 2496-2497.

Soldevilla, C., Vázquez, C., Patiño, B., Jurado, M., González-Jaén, M.T., 2005. Hongos toxicogénicos asociados a trigos y cebadas de Castilla y León. Boletîn de Sanidad Vegetal. Plagas 31, 519-529.

Somma, S., Alvarez, C., Ricci, V., Ferracane, L., Ritieni, A., Logrieco, A., Moretti, A. 2010. Trichothecene and beauvericin mycotoxin production and genetic variability in Fusarium poae isolated from wheat kernels from Italy. Food Additives and Contaminants $27,729-737$.

Steenkamp, E.T. Wingfield, B.D., Desjardins, A.E., Marasas, W.F.O., Wingfield, M.J. 2002. Cryptic speciation in Fusarium subglutinans. Mycologia 94, 1032-1043.

Swofford, D., 2003. PAUP: Phylogenetic Analysis Using Parsimony (and Other Methods): Version 4.0 b10. Sinauer Associates, Sunderland, MA.

Trenholm, H.L., Friend, D., Hamilton, R.M.G., Prelusky, D.B., Foster, B.C., 1989. Lethal toxicity and nonspecific effects. In: Trichothecene Mycotoxicosis: Pathophysiologic Effects, vol. 1. CRC Press, Florida, USA, pp. 107-142.

Wing, N., Lauren, D.R., Bryden, W.L., Burgess, L.W., 1993. Toxicity and trichothecene production by Fusarium acuminatum subsp. acuminatum and Fusarium acuminatum subsp. armeniacum. Natural Toxins 1, 229-234.

Wing, N., Bryden, W.L., Lauren, D.R., Burgess, L.W., 1994. Toxigenicity of Fusarium species and subspecies in section Gibbosum from different regions of Australia. Mycological Research 97, 1441-1446.

Xu, X.M., Parry, D.W., Nicholson, P., Thomsett, M.A., Simpson, D., Edwards, S.G. Cooke, B., Doohan, F., Brennan, I., Morett, A., Tocco, G., Mule, G., Hornok, L., Giezey, G., Tatnell, J., 2005. Predominance and association of pathogeneic fung causing Fusarium ear blight in wheat in four European countries. European Journal of Food Pathology 112, 143-154.

Xu, X.M. Nicholson, P., Thomsett, M.A., Simpson, D. Cooke, B.M., Doohan, F.M. Brennan, J., Monaghan, S., Moretti, A., Mule, G., Hornok, L., Beki, E., Tatnell, J., Ritieni, A., Edwards, S.G., 2008. Relationship between the fungal complex causing Fusarium head blight of wheat and environmental conditions. Phytopathology $98,69-78$. 